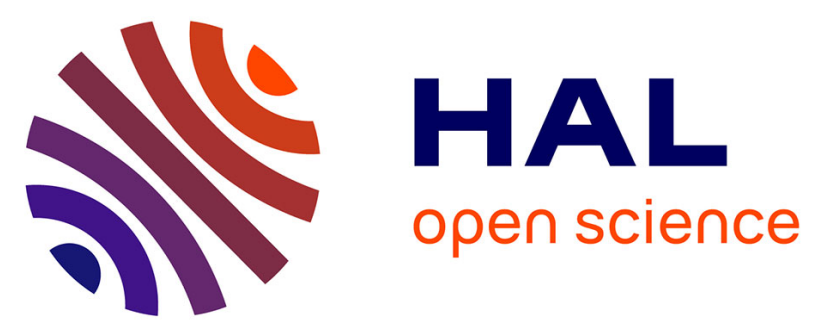

\title{
Lifestyles, sexuality and gender: vulnerability to STIs and unplanned pregnancy among female migrant beer promoters in Lao PDR
}

Vanphanom Sychareun, Jo Durham, Molina Choummanivong, Chansathit Taikeophithoun, Phouthong Phommavongsa, Vathsana Somphet, Vassana Thammavongsa, Pascale Hancart Petitet

\section{To cite this version:}

Vanphanom Sychareun, Jo Durham, Molina Choummanivong, Chansathit Taikeophithoun, Phouthong Phommavongsa, et al.. Lifestyles, sexuality and gender: vulnerability to STIs and unplanned pregnancy among female migrant beer promoters in Lao PDR. Culture, Health and Sexuality, In press, 10.1080/13691058.2021.1913233 . hal-03225148

\section{HAL Id: hal-03225148 \\ https://hal.science/hal-03225148}

Submitted on 12 May 2021

HAL is a multi-disciplinary open access archive for the deposit and dissemination of scientific research documents, whether they are published or not. The documents may come from teaching and research institutions in France or abroad, or from public or private research centers.
L'archive ouverte pluridisciplinaire HAL, est destinée au dépôt et à la diffusion de documents scientifiques de niveau recherche, publiés ou non, émanant des établissements d'enseignement et de recherche français ou étrangers, des laboratoires publics ou privés. 


\section{Lifestyles, sexuality and gender: vulnerability to STIs and unplanned pregnancy among female migrant beer promoters in Lao PDR}

Vanphanom Sychareun, Jo Durham, Molina Choummanivong, Chansathit Taikeophithoun, Phouthong Phommavongsa, Vathsana Somphet, Vassana Thammavongsa \& Pascale Hancart Petitet

To cite this article: Vanphanom Sychareun, Jo Durham, Molina Choummanivong, Chansathit Taikeophithoun, Phouthong Phommavongsa, Vathsana Somphet, Vassana Thammavongsa \& Pascale Hancart Petitet (2021): Lifestyles, sexuality and gender: vulnerability to STIs and unplanned pregnancy among female migrant beer promoters in Lao PDR, Culture, Health \& Sexuality, DOI: 10.1080/13691058.2021.1913233

To link to this article: https://doi.org/10.1080/13691058.2021.1913233

Published online: 10 May 2021.

Submit your article to this journal $\sqsubset$

Q View related articles ¿

View Crossmark data 


\title{
Lifestyles, sexuality and gender: vulnerability to STIs and unplanned pregnancy among female migrant beer promoters in Lao PDR
}

\author{
Vanphanom Sychareun $^{\mathrm{a}}$ (D), Jo Durham ${ }^{\mathrm{b}}$ (D), Molina Choummanivong ${ }^{\mathrm{c}}$, \\ Chansathit Taikeophithoun ${ }^{a}$, Phouthong Phommavongsa ${ }^{a}$, Vathsana Somphet ${ }^{a}$, \\ Vassana Thammavongsa ${ }^{a}$ and Pascale Hancart Petitet ${ }^{d}$ \\ ${ }^{a}$ Faculty of Public Health, University of Health Sciences, Ministry of Health, Vientiane, Lao PDR; \\ ${ }^{\mathrm{b}}$ School of Public Health and Social Work, Faculty of Health, Queensland University of Technology, \\ Brisbane, Queensland, Australia; 'School of Public Health, University of Queensland, Brisbane, \\ Queensland, Australia; ${ }^{\mathrm{d}}$ Institut de Recherche pour le Développement, UMI 233 Trans VIHMI, Inserm \\ U 1175, University of Montpellier, Montpellier, France
}

\begin{abstract}
In Southeast Asia, many young rural female migrants supplement their income by working as beer promoters. This study examined how young, female beer promoters working in Vientiane Capital, Lao PDR, navigate intimate relations and sexual encounters and how their experiences create sexual vulnerabilities. A total of 30 female beer promoters aged 18-24 years old were recruited using snowball sampling. Repeated face-to-face in-depth interviews were undertaken and thematic analysis conducted to identify common themes. Most participants had their first coital experience pre-migration but living in the city introduced them to a larger pool of potential partners. Unprotected sexual intercourse was common, with young women usually deferring to their male partners preference for non-condom use. Working as beer promoters, the sexualised environment of the bar room promoted male ideals of femininity and exposed the young women to sexual harassment. While the young women used various strategies to assert their autonomy, and challenge unequal gender norms, the prevailing male hegemony acted to subvert female sexual agency. Leveraging young urban migrants' desire to complete education, live independently and postpone motherhood may provide opportunities to examine and challenge gender norms and harmful practices.
\end{abstract}

\section{ARTICLE HISTORY}

Received 17 August 2020

Accepted 1 April 2021

\section{KEYWORDS}

Rural-urban migrants; female beer promoters; gender norms; sexual risks; urban Lao alcohol; sales promotion

\section{Background}

In South-East Asia, approximately two in five people live in urban areas and this is expected to increase to two-thirds of by 2025 (Nauman et al. 2015; UNESCO 2018). Much of the increase in the urban population is driven by young, internal, single ruralurban adults seeking employment, higher education and better access to services 
(Nauman et al. 2015; UNESCO 2018). In the city, these young people are exposed to different social norms to those in rural areas, with these new norms shaping their experience of the city as they become more independent in an urban environment (Anglewicz, VanLandingham, and Phuengsamran 2014; Ma and Cheng 2005).

Young people's experience of rural-urban migration is shaped by gender norms and the power relations enacted in everyday life, which create opportunities and risks for young migrants (Zhang 2014). Opportunities for women can include greater access to education and economic resources and increased independence. Women's access to work however, is also shaped by gender norms that reinforce perceptions about women's role in society and at home (Yeoh 2016). At the same time, migration, economic participation, increased independence and exposure to new ideas can help young women challenge entrenched oppressive gender norms (Yeoh 2016). Challenging gender relations may extend to exploring different ways of creating intimate relationships and sexual encounters, potentially developing more control over their bodies, but also potentially exposing them to new sexual vulnerabilities, the risk of sexually transmitted infections (STIs) and unplanned pregnancy (Swasti Centre 2018; Anglewicz, VanLandingham, and Phuengsamran 2014; Ma and Cheng 2005; Lyttleton 2014; Sychareun et al. 2016; Sychareun et al. 2018). Studies have found, for example, an association between rural-to-urban migration and early sexual debut (Mberu and White 2011; Luke et al. 2012), increased sexual activity, increased numbers of sexual partners and unprotected sex (Anglewicz, VanLandingham, and Phuengsamran 2014; Gaetano and Jacka 2004; Welz et al. 2007) and increased gender-based violence (Gaetano and Jacka 2004; Anglewicz 2012; Philip, Mark and Dusita 2014; Yeoh 2016).

Over the last decade, the Lao People's Democratic Republic (Lao PDR), a lower-middle income country in South-East Asia, has experienced high economic growth with the shift from a command to a more liberal economy (Lao Statistics Bureau 2016). While most of the population still reside in rural areas, internal rural-urban migration contributes to rapid urban growth (Lao Statistics Bureau 2016; Epprecht, Bosoni, and Hayward 2018). As in other countries within the region, internal rural-urban migration is female-dominated, with young women under 25 years of age constituting approximately $60 \%$ of internal migrants (Lao Statistics Bureau 2016). Many move to Vientiane Capital to pursue higher education or find work as they pursue modernity, independence, and support families at home (Epprecht, Bosoni, and Hayward 2018; Rigg 2009).

Female migrants are mostly employed in low-paid work in the informal sector or textile and manufacturing industries (approximately 30,000) (Lao Statistics Bureau 2016). An estimated 8,000 to 10,000 female migrants in Vientiane Capital work in the night-time economy in bars, beer shops and nightclubs, with a proportion working as beer promoters, earning commission on beer sales (Webber and Spitzer 2010). As in other countries in the region, women who work in the night-time economy are often stigmatised and associated with the exchange of sex for money (Sychareun et al. 2016; Webber et al. 2012).

Beer promotors are usually young women hired by breweries to market the company's beer in restaurants, karaoke parlours, beer shops and other entertainment venues. Working conditions are generally poor with limited-or no-social protection or paid leave (Sychareun et al. 2016; Webber et al. 2012). Typically, they wear tight-fitting, revealing clothes, and are expected to act as attentive hosts, creating an enjoyable 
atmosphere for customers (Sychareun et al. 2016; Webber and Spitzer 2010; Webber et al. 2012). The sexualised nature of bar work can contribute to beer promoters' exposure to sexual harassment including sexual teasing, jokes, pressure for dates, and deliberate touching or pinching, and transactional sex. (Sychareun et al. 2016). Within this context, there is concern female migrants working as beer promoters may be at risk of STIs/HIV and unplanned pregnancy. In a study in Cambodia, Thailand, Vietnam and Lao PDR for example, Webber and colleagues reported one third of beer promoters interviewed engaged in transactional sex and over half had experienced an abortion (Webber et al. 2012).

Despite the number of female migrants working as beer promoters in Southeast Asia including Cambodia, Thailand and Vietnam (Webber and Spitzer 2010), few studies have examined how beer promoters experiment with, and build, intimate relations within and outside the workplace, or how these experiences are shaped by their employment as a beer promoter. In this study, we address this gap by revealing how relocation to the city enables beer promoters to pursue their economic and educational goals, while also providing them increased exposure to new ideas and opportunities to engage in a much wider range of social interactions than those in their sending communities.

\section{Methods}

In this qualitative study we interviewed female beer promoters using repeat in-depth interviews (IDIs). The study site comprised three urban districts (Chanthabury, Sisattanak and Saysettha districts) in Vientiane Capital.

\section{Study participants and sampling}

The study population was young female beer promoters in Vientiane Capital. All were aged between 19 and 25, students and unmarried. Inclusion criteria were: 1) female beer promoters from diverse socio-demographic backgrounds, including different ethnicities and from different beer companies; 2) simultaneously studying and working as a beer promoter; 3) aged 18-year-old and older, 4) being a migrant from another province; and 4) living in Vientiane Capital for at least 6 months. Participants had to fulfil all the criteria to be eligible. Exclusion criteria were holding citizenship other than Lao, and/or showing signs of physical and/or psychological health impairment.

Prior to recruitment, the research coordinators met with the division of marketing of the two main beer companies in Lao PDR and three beer promotion supervisors to explain the objectives of the project, target group and data collection process. The marketing division manager in each of the companies provided the researchers with a contact list of beer promoters in the different districts in Vientiane Capital. In total, we recruited 30 beer promoters into the study. Eleven of the beer promoters who were invited to participate in the study either refused or dropped out at the second interview.

\section{Data collection and recruitment procedures}

Interviews were conducted face-to-face at a time and place convenient for the participant. An interview guide was used and included questions related to socio-demographic 
information (age, sex, education, ethnicity, marital status, parenthood, family, occupation nature of labour, working conditions), as well as information related to daily activities. The last part of the interview focused on more personal questions related to sexuality, premarital sex and transactional sex before and after migration. Participants were asked about their relationships with their communities (friends, boyfriends, relatives and parents), and their expectations. Using the same interview guide, each participant was interviewed twice to add to, or clarify, information from the previous interview. In the second interview, participants tended to elaborate further on their sexual relationships.

\section{Translation}

Interviews were conducted in the Lao language, recorded, transcribed in Laotian and then translated into English. While we did not back translate, to minimise the loss of meaning in the translation process, we rechecked the translation with a second translator and where there were discrepancies, returned to the recordings.

\section{Data analysis}

We conducted a deductive and inductive thematic analysis based on pre-formulated and emerging themes and following Clarke and Braun (2017). Preformulated themes included sexual risk, sexual infection, and workplace harassment. Identifying themes involved careful reading and re-reading of the transcripts, generating codes and identifying patterns to build a narrative from the data. A code book was developed for all transcripts, with two researchers coding the data independently, comparing analyses, and then discussing any differences in interpretation.

\section{Ethics}

The protocols for individual interviews received institutional review board (IRB) approval from the National Ethics Committee for Health Research, at the Ministry of Health, Lao PDR. Subsequent to ethics approval, verbal consent was obtained from each participant prior to interviews. Privacy and confidentiality were guaranteed, and participants were informed participation was voluntary, and they could withdraw from the interview any time without notice or without consequences. A small payment of 50,000 kip (4.5 USD) was given to participants at the conclusion of the interview as a token of appreciation for their time, although participants were not aware of this payment in advance. All identifying information was removed from the audio-recordings and transcriptions, with each participant allocated a pseudonym.

\section{Findings}

\section{Socio-demographic characteristics of beer promoters}

Participants ranged in age from 18-24 years (18-21, $n=14 ; 23-24, n=16)$. Almost all $(n=29)$ were of Lao ethnicity while one identified as Hmong-Mien. All participants had worked as beer promoters for over one year. 
All participants were single and had completed high school (Table 1). Prior to moving to Vientiane Capital, most participants had lived at home with their family. All participants had established family, friendship or acquaintance networks in Vientiane, which facilitated the process of migration and finding employment.

Participants' narratives suggested they had internalised significant aspects of their gendered social role. Through family instructions, they learned how to behave and relate to others, including in obedience to men, adopting a caretaking role, and remaining at home in the evening. While at home, some participants had also worked to save for their move to Vientiane and continue study. As one of the beer promoters explained:

After finishing high school, I sold goods at the grocery store in the village for 2-3 years to save money in order not to place a financial burden on my parents. Then I decided to come to Vientiane to continue my study at financial accounting school. (Noy, 25 years old)

\section{Moving to Vientiane capital}

On moving to Vientiane Capital, most participants lived with immediate or extended family or friends, helping their host with the housework tasks traditionally assigned to women. Tuition and living expenses were usually covered by family members. As these young women became more familiar with urban life and a modern, consumerorientated economy, their aspirations and expectations changed. Many yearned for more autonomy, privacy and economic freedom and sought accommodation separate from family members. All participants, for example, moved from their relatives to rent a room, usually in dormitory accommodation or sharing with a girlfriend.

The reason for moving away from my relative's house was because at my relative's house, there are many people staying in the house, and I wanted some privacy. (Vieng, 19 years old)

Some participants, not wanting to overtly challenge parental authority, moved out of their relative's house without informing their parents first, as they worried their parents would forbid them to do so, or would be angry with them for contravening rural gender norms whereby young, single women remain in their natal home:

I stayed with my aunt for about 1 year. In 2013, I moved from my aunt's house and rented a room with my girlfriend. I did not tell my parents at the beginning, as I was worried that my parents would not allow me to move out. (Keo, 20 years old)

\section{Becoming and acting as a beer promoter}

Participants identified several motivations for working as a beer promoter. The first related to their filial obligation to support their natal family. Beyond this, there was the desire to move into their own accommodation with more autonomy and the ability to participate in activities beyond study and home.

Participants had learned about opportunities of working as a beer promoter through family networks, neighbourhood ties and other students. Some participants 
Table 1. Socio demographic characteristics of study participants.

\begin{tabular}{|c|c|c|}
\hline Variable & $\mathrm{N}(30)$ & $\%$ \\
\hline \multicolumn{3}{|l|}{ Age } \\
\hline Mean & 21.8 & \\
\hline Min & 19 & \\
\hline Max & 25 & \\
\hline $18-21$ & 14 & 46.7 \\
\hline $22-24$ & 16 & 53.3 \\
\hline \multicolumn{3}{|l|}{ Ethnicity } \\
\hline Lao & 29 & 96.7 \\
\hline Hmong-Mien & 1 & 3.3 \\
\hline \multicolumn{3}{|l|}{ Place of study } \\
\hline National university of Lao PDR & 7 & 23.3 \\
\hline College of Financing & 14 & 46.7 \\
\hline Law school & 6 & 20.0 \\
\hline Banking College & 2 & 6.7 \\
\hline National Institute of Fine Arts & 1 & 3.3 \\
\hline \multicolumn{3}{|l|}{ Year of study } \\
\hline \multicolumn{3}{|l|}{ Mean } \\
\hline Year 1-2 & 7 & 23.3 \\
\hline Year 3-4 & 23 & 76.7 \\
\hline \multicolumn{3}{|l|}{ Province of origin } \\
\hline Northern & 18 & 60.0 \\
\hline Central & 5 & 16.7 \\
\hline Southern & 7 & 23.3 \\
\hline \multicolumn{3}{|l|}{ Length of time living in Vientiane } \\
\hline$<4$ years & 11 & 36.7 \\
\hline$>4$ years & 19 & 63.3 \\
\hline \multicolumn{3}{|c|}{ Length of time working as a beer promoter } \\
\hline $1-2$ years & 13 & 43.3 \\
\hline$>2$ years & 17 & 56.7 \\
\hline \multicolumn{3}{|l|}{ Father's education } \\
\hline \multicolumn{3}{|l|}{ Illiterate } \\
\hline \multicolumn{3}{|l|}{ Primary } \\
\hline \multicolumn{3}{|l|}{ Lower secondary } \\
\hline \multicolumn{3}{|l|}{ Upper secondary } \\
\hline \multicolumn{3}{|l|}{ Post-high school 6} \\
\hline Illiterate & 4 & 13.3 \\
\hline Primary & 4 & 13.3 \\
\hline Lower secondary & 8 & 26.7 \\
\hline Upper secondary & 6 & 20.0 \\
\hline Post-high school 6 & 8 & 26.7 \\
\hline \multicolumn{3}{|l|}{ Mother's education } \\
\hline Illiterate & 4 & 13.3 \\
\hline Primary & 9 & 30.0 \\
\hline Lower secondary & 10 & 33.3 \\
\hline Upper secondary & 7 & 23.3 \\
\hline \multicolumn{3}{|l|}{ Father's work } \\
\hline Public servant & 7 & 23.3 \\
\hline Private employee & 5 & 16.7 \\
\hline Seller & 5 & 16.7 \\
\hline Farmer & 9 & 30.0 \\
\hline Not working & 3 & 1.0 \\
\hline Deceased & 1 & 3.3 \\
\hline \multicolumn{3}{|l|}{ Mother's work } \\
\hline \multicolumn{3}{|l|}{ Public servant } \\
\hline Private employee & 4 & 13.3 \\
\hline
\end{tabular}


Table 1. Continued.

\begin{tabular}{lcr}
\hline Variable & $\mathrm{N}(30)$ & $\%$ \\
\hline Seller & 4 & 13.3 \\
Farmers & 9 & 30.0 \\
Housewife & 8 & 26.7 \\
Weaving & 4 & 13.3 \\
Deceased & 1 & 3.3 \\
Participants' perceived family socio-economic status & & \\
Wealthy & 0 & 0 \\
Middle & 29 & 96.7 \\
Poor & 1 & 3.3 \\
\hline
\end{tabular}

said they had talked about their intention to apply to be a beer promoter with family members and/or friends in the capital but rarely with their parents. Reasons for not doing so related to their fear of parental disapproval, awareness of stigmatising discourses related to women working in bars, and bar work's association with sex work. Being a beer promoter meant shouldering a stigma not applied to the patrons of such venues.

Other people see girls who are doing this job as not a good person. (Lai, 20 years old)

Caught between rural norms and a modern, consumerist lifestyle, working as a beer promoter challenged both parental authority and the conventional qualities ascribed to a "virtuous" woman: chastity before marriage, domesticity within it, and childrearing. Having friends or other family members working as a beer promoter however, helped ease the way and introduced participants to the practicalities the work.

Beer promoters typically started work at 6 p.m. and finished around 10.30 p.m. A van from the brewery collected them, took them to work and took them back home at the end of their shift. Most promoters worked six days a week, earning around 50,000 kip per day (4.5 USD), supplemented by tips, bonuses and additional promotional work. While expected to socialise with patrons, beer promoters were not allowed to drink beer with customers. In our observations, we saw how for some participants playing the attentive host was relatively easy, others seemed shyer.

The brewery provided the young women with a branded, close-fitting, and revealing uniform, emphasising their femininity. The brewery also provided training on how to "be" a beer promoter, including bodily appearance and comportment, and how to make customers feel comfortable. As one person explained:

I went to training on how to welcome the customers, serving beer, how to stand and how to walk. (May, 22 years old)

The training implies that sexual harassment was an inevitable part of the job. Young women were instructed in how to "handle" it, suggesting that in the bar setting, sexual harassment is acceptable and making the definition of sexual harassment for these young women ambiguous. One participant explained she had been taught:

How to promote beer, and [the] skills to negotiate with all guests including those who are impolite or drunk. (Davanh, 21 years old) 
For some men buying beer was the first step towards establishing rapport, and some participants met their sexual partners at work. All participants reported instances of sexual harassment, including unwanted touching and sexual propositions.

... [when] I'm pouring beer for clients, I have to be careful and try to avoid [them touching me]. (Pinky, 25 years old)

Participants reported how in cases of sexual harassment, being careful not to upset the customer or venue owner, they adopted a traditional submissive female role, politely tolerating sexual/romantic overtures, or employing indirect methods, such as smiling, staying silent and moving away as they as they had been trained.

Other strategies the women used to maintain some control, included giving incorrect phone numbers, not answering their customers suggestive questions and protecting their female colleagues. In suppressing their emotions, thoughts and behaviour, and by using strategies of avoidance, beer promoters reinforced traditional gender roles, practices and power relations:

\footnotetext{
When I go to work, I am sometimes asked for my phone number, so I give my old number. If the clients are old, I give my phone number but when they call me, I don't pick it up. I have also been asked questions about my friends. For instance, if a client asks me, "Do you know if your friends could go out with me?" He would ask, "Does your friend 'hubkhek'? "Hubkhek" (means go out with client and having sex with a patron after work). I just avoid answering the question by saying I will ask her later. (Nina, 19 years old)
}

Participants noted that when they served men who were with their girlfriends, the man's girlfriend often reacted negatively towards the beer promoters. Participants explained how in cases where they were harassed or felt uncomfortable, the team leader often responded in a supportive way:

When I was upset due to client's bad behaviours my leader helps me, he's a supportive and kind person. (Chandara, 20 years old)

While team leaders may be "supportive and kind", neither team leaders nor venue owners approached customers regarding their inappropriate behaviour. The overtones of sexuality associated with being a beer promoter may account for the lack of intervention by venue owners, who may share some of the same perceptions as their patrons. In this way, the discourses surrounding beer promoters and the discursive practices reinforce the gender roles and norms that underlie sexual/romantic overtureharassment and dominant ideals of masculinity. Gender differences between beer promoters and their often-older male patrons, and beliefs about what is expected from them, reinforced oppressive gender and power relations and strengthen the sexualisation of women.

\section{Sexual debut and early sexual experience}

Most respondents had met their first boyfriend prior to migrating. Many had their sexual debut with their first boyfriend during high school, mostly around the age of 16 . In these early sexual relationships, most participants partnered with someone similar in age to themselves. The relationship often started by a friend or relative introducing 
the couple and continued via face-to-face meetings, telephone and apps such as WeChat, lasting perhaps for 2-3 years.

Relationships typically moved from hand holding and touching to sexual intercourse, with first coitus often being unplanned, while alcohol intoxicated, and in a guesthouse paid for by the male partner. The expectation that the male partner would pay for the room seemed gendered, with no participant questioning this, or intimating that men might expect their girlfriends to pay for the room. Despite the use of alcohol at first intercourse, and the initiation of sex by the male partner, most participants said their first sexual experience was consensual, taking place within the context of a romantic relationship.

During our relationship, we went to a friend's birthday party, my boyfriend came with me and later took me to a guesthouse as he asked me, and I also agreed to go to the guesthouse (for sex). (Vanh, 21 years old)

Participant narratives highlighted how by the time of their first relationship and sexual experience, gender norms were already internalised. For example, while several participants asked their male partners to use a condom during sex, most were unable to insist on condom use, due to the male partner's preference for withdrawal. Concerned to please their boyfriends, young women in this study typically compromised their desire to use a condom and avoid unplanned pregnancy. Participants also revealed how the withdrawal method could fail, especially when the couple had been drinking alcohol.

One participant described having been raped by a boy she was seeing at school, but she was too afraid to disclose the incident to any adults.

\footnotetext{
He took me through the forest, and he raped me. I screamed and argued because I didn't want to have sex with him. I asked him, "Aren't you ashamed if someone comes and sees us". I cursed him, cried and screamed. He didn't use a condom and after that took me to my uncle's home. I told my sister and [my] uncle's daughter-I was too scared to tell adults. [All] that month, I was worried about being pregnant until my period started, I felt relieved. I [later] met him at school, I didn't talk to him, and didn't look at his face because I hated him. (Phonethip, aged 21 years old)
}

Another participant, Souvanna, reported having coercive sex with a friend of the family when she was 16 years old. The participant explained she then fell in love with this man who became her regular sexual partner. While not clear in the interview, being in a legitimate relationship with the man may have helped this young women manage her feelings relating to having initially being coerced into sex. According to Vilay, from their first sexual encounter the man had given her a "gift" of cash, and subsequently regularly gave her financial or other material gifts.

\section{Sexuality, intimacy and new forms of conjugality}

All the study participants had moved to Vientiane Capital primarily with educational goals in mind and the desire to postpone marriage and motherhood until after completing their study. In Vientiane, participants met boyfriends while studying, at work or with friends and typically entered a sexual relationship one or two weeks after the first meeting. Few mentioned having met sexual partners via social media. Partly due 
to living in shared accommodation, sexual intercourse with their boyfriends usually occurred in hotels or guest houses, with the cost as in their earlier sexual experiences, covered by their boyfriends.

While most of the sexual encounters were with serial sexual partners and were reported as consensual, participants described control by men within these relationships. As in their pre-migration sexual experiences, despite wishing to avoid pregnancy, participants were concerned that negotiating condom use might make them seem sexually assertive or questioning of their partners fidelity, contributing to a "silencing of condom negotiation" (Teitelman et al. 2011: 249). Rarely did participants describe not using condoms for their own sexual pleasure. Neither did they describe exercising their own sexual agency such as testing for STIs, discussing STI/HIV prevention with their partners or avoiding unwanted pregnancy.

Participants engaged in sexual intercourse to experience positive emotions such as intimacy and love, which also contributed to non-condom use.

We love each other, and he will marry me if I get pregnant. (Yai, 21 years old)

Young women's intimate relationships were often connected to money or material support. Their boyfriends for example, often provided gifts and material and/or emotional support, with little suggestion the women should provide gifts in return to their male partners. The link between being a beer promoter and involvement in sex work was strong, however, and could prevent relationships forming or be a reason for a boyfriend leaving. Having multiple sexual partners, concurrently or consecutively, was common. Some young women reported having multiple sexual partners after betrayal by a partner, while others became involved in casual sex, seeking material goods and comfort. As Vanida explained,

Casual partners can be unintentional. I thought that he was sincere with me, he was smart. Because I didn't want to go myself [to a nightclub], I took two friends with me. He also brought two friends with him. We divided in couples, s each couple went to karaoke and we drunk until we were drunk. We ended up in having sex at the guest house. After that, I didn't see him anymore. (Vanida, aged 19 years old)

Several participants had met their casual or regular partners at work or through fellow beer promoters. Often these male partners were older and of higher social and economic status than the beer promoters and paid for everything when they went out together. Participants explained these boyfriends would often "understand" they worked as beer promoters but sometimes encouraged them to leave and be supported in other ways. From interviews, it did not seem that these men were proposing long-term, stable relationships. One participant revealed having an older lukha pacham (sugar daddy) whom she met at work and saw as a of means meeting her material needs.

My partner is a businessman and is over 60 years old. I met him at a ceremony at a house where I served beers, six months ago. I agreed to sleep with him as I was willing to exchange sex for cash and to have things I need. As he's old, I didn't like him. I felt shy or embarrassed when I was going out with him. I didn't do anything to prevent pregnancy. He wanted me to take contraception pills, but I wanted him to use condoms. He said that he doesn't sleep with anyone else, except me. If he gets STIs, it would be from me. So, I just listened to him. I did what he wanted as he gave me a lot of money. (Vieng, aged 19 years old) 
In the city, with less family oversight over their personal lives, young women in this study were able to explore different ways of conducting relationships. Despite the new and seemingly "liberated" rules of engagement however, traditional gender dynamics persisted with the male partner initiating the demand for sex, paying for the location in which to have sex, and managing (or not) contraceptive use.

\section{Reproductive and infectious risks}

Being expected to appear chaste and sexually naïve, participants had limited knowledge related to STIs, with participants mostly learning about STIs from their peers or the Internet. Many reported feeling that being in a loving and trusting relationship, they were not at risk of STIs. None of the participants had been tested for STIs or HIV or had asked their partners to be tested before initiating sexual relationship. Neither were they able to differentiate between different STls such as Chlamydia or gonorrhoea. A few participants reported experiencing vaginal discharge with a bad smell, which they self-treated with traditional herbal medicine, douching with vinegar or herbal solutions, or using suppositories from the local pharmacy. Participants were mostly unaware where they could be tested for STIs or that both partners needed treatment is an STI was acquired.

I want to check for STIs, but I don't know where I can get the test... I don't know what kind of medicine I should buy. I explained my symptoms to the pharmacist who gave me medicine to treat it. My boyfriend doesn't take medicine because he doesn't have any symptoms. So why he should have it? (Nalee, 23 years old)

Women revealed that some of the men they had sex with had concurrent sexual partners, but this did not necessarily encourage them to negotiate condom use. Participants often accepted their partners' concurrency based on an the understanding that men will have multiple sexual partners. Participants recognised their bargaining power in relation to condom use was weak and attempting to do so opened them to allegations of being untrustworthy or suggesting their male partner was unfaithful. Thus, while afforded greater sexual agency than their counterparts in rural areas or in previous generations, young women negotiated their premarital relationships, and the sexual risks embedded in them, in line with prevailing gender norms.

That said, the risk of pregnancy was a great concern to participants, and few reported using or having information about modern contraceptives other than condoms. A few participants reported having had to terminate a pregnancy, usually because they felt they were not ready for motherhood.

I recently had an abortion. I got pregnant with my current boyfriend; we were drunk, and we didn't use condom to prevent pregnancy. (Nalee, aged 23 years old)

Some participants reported buying tablets at a pharmacy, often a Chinese brand (known locally as ya chine, and readily purchased over the counter at a pharmacy, to induce abortion. Others said that if pregnant, they would willingly purchase ya chine rather than consult a health professional. Just a few participants had taken the emergency contraceptive pill. Thus, while not very successful at negotiating condom use or the use of other modern contraceptives, young women made efforts to gain control 
over their reproductive health and, in the process, sought means to exercise agency and postpone childbirth and, in doing so, challenge rural community values in which young motherhood was the norm.

\section{Discussion}

Moving to the city provided women in this study with new economic opportunities, exposed them to new ideas and introduced them to a larger pool of potential sexual, romantic partners. Working as beer promoter provided a level of financial independence and facilitated more independent living and opportunities for sexual exploration. In the city, exposed to new norms, young women pursued sexually intimate relationships for love and pleasure, rather than simply reproduction. Working as a beer promoter also provided opportunities for them to encounter potential male partners of higher social and economic status who introduced them to new social networks.

While challenging the idea of engaging in sexual relationships only for reproductive purposes, women in this study were aware of the gender norms and double standards that pervade sexual practice (Anglewicz, VanLandingham, and Phuengsamran 2014; Ma and Cheng 2005). Participants were careful not to raise condom use with their male sexual partners for fear of being judged as too sexually experienced. The idea that requesting condom use suggests a permissiveness can create ambivalence about the use of condoms in intimate relationships, reducing female agency (Teitelman et al. 2011). While trust was given as a dominant reason for not using condoms, this trust was seldom based on the results of negative STI/HIV tests or discussion about sexual history, with interviews suggesting instead that young women had internalised sociocultural assumptions that privilege male sexual pleasure. By acting to preserve the established (male-dominated) gender order, however, young women could be exposed to sexual health risks including unplanned pregnancy, unsafe abortion and STIs, including HIV.

Working as a beer promoter creates specific vulnerabilities that are different those of young female migrants working in other sectors. Employing attractive young females as beer promoters, who are trained in how to interact with customers, deliberately sexualises young women and reinforces unequal power relationships (Coffey et al. 2018). Within such an environment, female beer promoters are exposed to sexual harassment and unwanted sexual attention by male patrons. Unwanted sexual attention is facilitated by the bar environment, in which young women's role is to create a pleasurable environment so the (mostly male) patrons purchase more beer (Sychareun et al. 2016; Webber and Spitzer 2010). The training that beer promoters receive, as well as the desire to maintain their job, encourage young women to passively accept male sexual overtures as they "do" deference to their male customers (Good and Cooper 2016; Poulston 2008; Coffey et al. 2018) further subverting female agency.

Working in a sexualised workplace also exposes female beer promoters to stigma at many levels, from general society, male clients, family members and healthcare workers, due to the perceived association between beer promotion with sex work (Sychareun et al. 2016; Webber and Spitzer 2010). The association of beer promotion with bar work and beer promoters' performance of specific kinds of femininity, may also lead men to think promoters should expect, or "want", to be the targets of sexual 
overtures, especially when beer promoters use indirect methods of discouragement, such as smiling and moving away. In the long term, some of the romantic/sexual overtures made by male patrons towards the female beer promoters may be genuine or accepted by the women and develop into meaningful relationships, while others may be more transactional in character (Webber and Spitzer 2010).

\section{Limitations}

This study has some limitations. First, the sample was relatively homogeneous, perhaps due to the type of sampling employed. We have not, therefore, captured the full range of experiences of urban female migrants working as beer promoters. In particular, it is possible we excluded women who experience not only gender inequalities but also, other structural inequalities related to minority ethnicity that further limit opportunities of claiming sexual agency.

Study transcripts were translated from the Lao language into English, and some meaning may have been lost in the process. However, where there was ambiguity, we did return to the Lao language transcript to confirm understanding. As is common in sex research, we took informants' verbal accounts for granted, and used them as products ready for analysis. However, embodied experiences are often hard to communicate, especially when the experiences and feelings are talked about with an unfamiliar researcher. Participants may have kept silent about their experience challenging normative interactions and may have been more informed about sexual health, condom use and initiating sex than they revealed in interviews. Similarly, experiences of sexual harassment in venues, or when exchanging of sex for money may have been omitted. Such omissions have cultural significance in the context we described.

\section{Conclusion}

The paper extends and reinforces the limited body of literature on sexual intimacy and health risk among beer promoters in South East Asia. Moving from a rural to an urban area provides young women with new economic opportunities, exposure to new ideas and access to a larger pool of potential sexual, romantic partners. Gender norms and inequality, patriarchal power relations, and social and cultural attitudes, however, can subvert female sexual agency and potentially expose beer promoters to sexual risks and harassment. Nevertheless, while sometimes constrained, young women can exercise agency, employing various strategies to retain a degree of control over their bodies and maintain their dignity in the workplace. Leveraging young urban migrants' desires to complete their education, live independently and postpone motherhood may provide opportunities to examine and challenge gender norms and harmful practices.

\section{Acknowledgements}

This study was conducted as part of the "Migration, Mobilities and HIV/STI Vulnerabilities" research project. We to thank the IRD Croix Rouge Française for support during the study. We 
also thank the study participants, and Naomi Stekelenburg and John Cauchi for editing support while preparing this paper for submission.

\section{Disclosure statement}

No potential conflict of interest was reported by the author(s).

\section{Availability of data and material}

Summaries of quantitative interviews and other materials used in this article can be accessed by sending a request to the first author.

\section{Funding}

Funding for the study was provided by Expertise France/French Red Cross (Grant number 13INI207), PI. Pascale Hancart Petitet.

\section{ORCID}

Vanphanom Sychareun (iD http://orcid.org/0000-0002-4313-7336

Jo Durham (iD http://orcid.org/0000-0003-0544-9424

Pascale Hancart Petitet (iD http://orcid.org/0000-0002-7377-8038

\section{References}

Anglewicz, P. 2012. "Migration, Marital Change, and HIV Infection in Malawi." Demography 49 (1): 239-265.

Anglewicz, P., M. VanLandingham, and D. Phuengsamran. 2014. "Rural-to-Urban Migration and Sexual Debut in Thailand." Demography 51 (5): 1955-1976.

Clarke, V., and V. Braun. 2017. "Thematic Analysis." The Journal of Positive Psychology 12 (3): 297-298.

Coffey, J., D. Farrugia, L. Adkins, and S. Threadgold. 2018. "Gender, Sexuality, and Risk in the Practice of Affective Labour for Young Women in Bar Work." Review of Sociological Research Online 23 (4): 728-743.

Epprecht, M., N. Bosoni, and D. Hayward. 2018. Urbanization Processes in the Lao PDR: Processes, Challenges and Opportunities. Bern: Centre for Development and Environment, University of Bern, Switzerland.

Gaetano, A., and T. Jacka 2004. On the Move: Women and Rural-to-Urban Migration in Contemporary China. edited by Arianne M. Gaetano and T Jacka, 1-38. New York: Columbia University Press.

Good, L., and R. Cooper. 2016. "But it's your Job to be Friendly': Employees Coping with and Contesting Sexual Harassment from Customers in the Service Sector." Gender, Work \& Organization 23 (5): 447-469.

Lao Statistics Bureau. 2016. The 4th Population and Housing Census (PHC) 2015. Vientiane Lao Statistics Bureau.

Luke, N., H. Xu, B. U. Mberu, and R. E. Goldberg. 2012. "Migration Experience and Premarital Sexual Initiation in Urban Kenya: An Event History Analysis." Studies in Family Planning 43 (2): $115-126$.

Lyttleton, C. 2014. Intimate Economies of Development: Mobility, Sexuality and Health in Asia. London and New York: Routledge. 
Ma, E., and H. Cheng. 2005. "Naked' Bodies: Experimenting with Intimate Relations Among Migrant Workers in South China." International Journal of Cultural Studies 8 (3): 307-328.

Mberu, B. U., and M. J. White. 2011. "Internal Migration and Health: Premarital Sexual Initiation in Nigeria." Social Science \& Medicine (1982) 72 (8): 1284-1293.

Poulston, J. 2008. "Metamorphosis in Hospitality: A Tradition of Sexual Harassment." International Journal of Hospitality Management 27 (2): 232-240.

Rigg, J. 2009. "A Particular Place? Laos and its Incorporation into the Development Mainstream." Environment and Planning A: Economy and Space 41 (3): 703-721.

Swasti Centre. 2018. Migration, Mobility and HIV: Asia Pacific Region Thematic Analysis Paper. Bangalore: Swasti Centre.

Sychareun, V., B. Santavasy, N. Chanlivong, A. Fischer, N. Thomson, R. Power, and J. Durham. 2018. "Methamphetamine-Type Stimulant Use in Lao PDR: Qualitative Findings from Users Aged 1525 years in Vientiane Capital and Vientiane Province." Harm Reduction Journal 15 (1): 17.

Sychareun, V., V. Vongxay, V. Thammavongsa, S. Thongmyxay, P. Phummavongsa, and J. Durham. 2016. "Informal Workers and Access to Healthcare: A Qualitative Study of Facilitators and Barriers to Accessing Healthcare for Beer Promoters in the Lao People's Democratic Republic." International Journal for Equity in Health 15 (1): 1-10.

Teitelman, A. M., J. Tennille, J. M. Bohinski, L. S. Jemmott, and J. B. Jemmott. 2011. "Unwanted Unprotected Sex: Condom Coercion by Male Partners and Self-Silencing of Condom Negotiation Among Adolescent Girls." ANS. Advances in Nursing Science 34 (3): 243-259.

UNESCO. 2018. Internal migration in Southeast Asia: An Initiative to Better Understand Migrants' Experiences and Develop Inclusive Policy Responses. Bangkok: UNESCO Office Bangkok and Regional Bureau for Education in Asia and the Pacific, United Nations Development Programme, International Organization for Migration, United Nations Human Settlements Programme.

Webber, G., and D. Spitzer. 2010. "Sexual and Reproductive Health Issues Facing Southeast Asian Beer Promoters: A Qualitative Pilot Study." BMC Public Health 10 (1): 389.

Webber, G., D. Spitzer, R. Somrongthong, T. C. Dat, and S. Kounnavongsa. 2012. "Facilitators and Barriers to Accessing Reproductive Health Care for Migrant Beer Promoters in Cambodia, Laos, Thailand and Vietnam: A Mixed Methods Study." Globalization and Health 8 (1): 21.

Welz, T., V. Hosegood, S. Jaffar, J. Bätzing-Feigenbaum, K. Herbst, and M.-L. Newell. 2007. "Continued Very High Prevalence of HIV Infection in Rural Kwazulu-Natal, South Africa: A Population-Based Longitudinal Study." AIDS 21 (11): 1467-1472.

Yeoh, B. 2016. "Migration and Gender Politics in Southeast Asia." Migration, Mobility, \& Displacement 2 (1): 75-88.

Zhang, N. 2014. "Performing identities: Women in Rural-Urban Migration in Contemporary China." Geoforum 54: 17-27. 